\title{
Marmara ve İstanbul Üniversiteleri Spor Bilimleri Fakültesi Öğrencilerinin Kitap Okumaya Yönelik Bakış Açılarının Değerlendirilmesi*
}

\author{
Emre TÜREGÜN** Asl1 KAYA***
}

\begin{abstract}
Özet
$\mathrm{Bu}$ çalışmada spor bilimleri fakültesi öğrencilerinin kitap okumaya yönelik bakış açıları ve tutumları incelenmek istenmiştir. Bu sürece gönüllü olarak Marmara ve İstanbul Üniversitelerinden $86 \mathrm{klz}(\% 40,2)$ ve $128(\%$ 59,8) erkek öğrenci katılmıştır. Veri toplama aracı olarak "Kitap Okuma Alışkanlığına İlişkin Tutum Ölçeği" ile araştırmacılar tarafinda geliştirilen "Kişisel Bilgiler Formu" kullanılmıştır. Tüm istatistiksel prosedürler için anlamlılık düzeyi 0,05 olarak alınmıştır. Tüm istatistiksel analizler SPSS paket programında yapıldı. Verilerinin analizinde t-testi, ANOVA ve Mann-Whitney U testinden yararlanılmıştır. Araştırmanın sonuçları Spor Bilimlerinde okuyan öğrencilerin okumanın yararına karşı olumlu tutumları olduğunu göstermiş̧tir. Ayrıca, spor bilimi öğrencilerinin kitap okumaktan hoşlanmadıklarını göstermiştir.
\end{abstract}

Anahtar Kelimeler: Spor, Kitap okuma, Tutum

\section{Evaluation of Perspectives of Marmara University and Istanbul University Faculty of Sport Sciences Students Toward Reading Habit}

\begin{abstract}
In this study, it was aimed to examine the perspectives and attitudes of students of sports sciences faculty of reading books. In this process, 86 female (40.2\%) and $128(59.8 \%)$ male students from Marmara and Istanbul Universities voluntarily participated. The data was collected through a 'Demographic Information Form' developed by the researcher and 'The Attitude Scale towards Reading Habit'. The level of significance for all statistical procedures was taken as 0.05. All the statistical analyses were made through SPSS package program. For analysing the data, Descriptive Statistics (frequencies (f), percentage (\%), Mean), t-test, ANOVA and Mann Whitney U tests were used. The results of the study showed that the students who studied Sports of Science had positive attitude towards benefit of reading. Furthermore, the results showed that sports science students didn't like reading books.
\end{abstract}

Keyword: Sport, Reading, Attitude

\footnotetext{
*Bu Çalışma Uluslararası Necatibey Eğitim ve Sosyal Bilimler Araştırmaları Kongresi Sözel Bildiri olarak sunulmuştur. ** Dr. Öğr. Üyesi Emre TÜREGÜN, Düzce Üniversitesi, Spor Bilimleri Fakültesi, Düzce, Türkiye, emreturegun@gmail.com

*** Aslı KAYA, Eskişehir Teknik Üniversitesi, Fen Fakültesi, İstatistik Ana Bilim Dalı, Eskişehir, Türkiye, $\underline{\text { asli.k@eskisehir.edu.tr }}$
} 


\section{GİRIŞ}

Gün be gün büyüyen dünyamızda, değişimin temelini okumak oluşturur. Okuma, bir birey olarak insanoğlunun kendini gerçekleştirme adına yapabileceklerini hissettiren özel bir eylemdir (Tokar, 2012). Okuma, anlamanın ve yorumlamanın en önemli basamaklarından biridir. Diğer dil becerilerini de içinde barındırmasından ötürü, okuma eğitimi daha çok önemsenmekte ve bu alanda yoğun çalışmalar yapılmaktadır (Aytaş,2005).

Dil becerilerinin temel yapı taşlarından biri okumadır. Bilgilerin, düşüncelerin, duyguların, hayallerin vb. pek çok durumun girdisi okuma eylemi ile gerçekleşmektedir. $\mathrm{Bu}$ dil becerisi, aynı zamanda zihinsel becerilerle de yakından ilgilidir (Edizer, 2015). Çünkü okuma, etkin bir işlem gerektirir (Edizer, 2015). Okuma insana farkl1 bakıș açıları kazandıran ve yaşamı yeniden anlamlandırmaya imkân veren becerilerdir (Kuşdemir ve Güneş, 2014).

Kısaca tanımlayacak olursak, okuma alışkanlı̆ğ; bireyin bir gereksinim ve zevk kaynağı olarak algilaması sonucu okuma eylemini yaşam boyu, sürekli, düzenli ve eleştirel bir biçimde gerçekleştirmesidir (Yılmaz, 2004). Okuma alışkanlığı yaşam boyu öğrenmenin temelidir. Bireyin yaşam boyu öğrenen bir kişi olabilmesi için okuma eylemini düzenli olarak gerçekleştirmesi gerekmektedir (Odabaş, Odabaş ve Polat, 2008). Yavuz (1996), kitap okuma işinin, alışkanlıktan ziyade bir yetenek işi olduğunu savunmaktadır. İlkokulda ortaya çıkan bu yeteneğin daha sonra geliştiğini ve özellikle lise döneminde bu yeteneğe yön verilmesi gerektiğini belirtmektedir.

Okuma becerisi çocuğun başta bilişsel ve sözel gelişim olmak üzere tüm gelişim alanlarında ilerlemesini sağlayan önemli bir beceridir. Okumanın alışkanlık hâline gelmesinde rol oynayan birçok etken bulunmaktadır. Bunlar arasında en başta çocuğun ailesi, sonra da içinde yaşadığ 1 toplum, okulu ve öğretmeni bulunmaktadır (Tanju, 2010).Çocukluktan başlayarak getirilen yaşantılar ve davranış özellikleri, eleştirel ve etkin bir okur olabilme bakımından oldukça önemlidir. Erken yaşta okuma becerisinin edinilmesi; aile ortamında okuma şansının bulunması, bu alışkanlığın ailede kazanılması, algılama ve merakını anlatma yeteneği ilk sosyal çevrede gelişir. Bu gelişme ile görsel medyanın, konuşma ve okuma yeteneğini köreltmesi engellenmiş olacaktır (Kanzog, 1974, aktaran; Aytaç, 2002).

Çeşitli bilgi kaynakları arasında kitaplar en eski ve önemli bir yere sahiptir. Kitaplar, bilgi sağlamanın yanı sıra, insanın tüm duygularına hitap etmektedir (Balat, 2002). Ayrica kitaplar, bireylerin entelektüel becerilerinin gelişmesine ve doğuştan gelen, zamanla körelmiş olan ama güdülebilen yaratıcılık yetisinin gelişmesine hız kazandırır (Bayındır, 2016). Kitap okumanın bu denli önem ve yararına rağmen, kitap okumaya karşı istenilen düzeyde ilginin sağlanamadığı da gözlenmektedir. Arıca'nın (2008) üniversite öğrencilerine uyguladığı anket sonucu genelde üniversite öğrencilerinin kitap okumayı sevmediği saptanmıştır. Ve okumayı sevmeyen öğrencilere neden okumay1 sevmediklerine ilişkin sorduğu sorular sonucunda öğrencilerin "kitapların bazılarını pahalı ve sıkıcı bulduklarını", "çocukken alışkanlık kazanmadıkları", "boş zamanlarının olmadığı”, "dergi okumayı, film izlemeyi ve internette dolaşmayı kitap okumaktan daha eğlenceli buldukları" yanıtlarını almıştır.

Esgin ve Karadă̆ (2000)' 1n, üniversite öğrencilerinin okuma alışkanlıkları ve kütüphane kullanımları üzerine yaptıkları çalışmada, öğrencilerin sadece \% 26'sının boş zamanlarında kitap okuduğu, \%20' sinin süreli yayın takip ettiği, sayısal ve sözel bölüm öğrencilerinin okuma alışkanlıklarının farklılık gösterdiğini tespit etmişlerdir. Araştırmacılar, öğrencilerin \%92' sinin yeterince kitap okumadığını kabul ettiğini ve okuyamama sebebi olarak "derslerden vakit kalmamasını" (\%46) gösterdiklerini belirtmişlerdir. Tel ve diğg. (2007), Beden Eğitimi ve Spor bölümü öğrencileriyle yaptıkları çalışmanın sonucunda, beden eğitimi ve spor bölümü öğrencilerinin kitap okuma alışkanlıklarının olmadığını ve boş zamanlarını çoğunlukla sportif faaliyetlerle 
geçirdiklerini bulmuşlardır. Öğrenciler arasında kütüphaneye gitme oranı çok düşük çıkmıştır. Çalışmada öğrenciler, kitap okumama nedenleri olarak televizyona fazla zaman ayırdıklarını ve okulun okuma alışkanlığı kazandırmadığını ifade etmişlerdir

Benzer sonuç Gömleksiz ve Telo (2003) tarafindan Eğitim Fakültesi öğrencileri üzerinde yapılan bir araştırma ile de belirlenmiştir. Araştırmada öğrencilerin üniversite kütüphanesini yeterli düzeyde kullanmadıkları ortaya konmuştur.

Özetle okuma, hayata anlam kazandırma sürecidir. Bilgiye sahip olmanın ve yeni bilgiler geliştirme arayışlarının oluşturduğu günümüz dünyasında, milletlerin ayakta kalması, bilgi teknolojilerini yönetebilmesi ancak toplumun okumaya ayırdığı zamanla doğrudan bağlantılıdır (Çoban, İleri ve Temir, 2008). Okuma alışkanlığı ile toplumların gelişmişlik düzeyleri arasında mutlak anlamda bir bağ bulunmaktadır (Arslan vd., 2009). Çağdaş, yaratıcı, yapıcı ve özgür düşünceye sahip, üretken, eleştirel bakan bireylerden oluşan bir toplum olmak ancak okuma bilinci aşılanmış bireylerle mümkündür (Kurulgan ve Çekerol, 2008).

Araştırmanın problem cümlesi; “İstanbul Üniversitesi ve Marmara Üniversitesi, Spor Bilimleri Fakültesi'nde öğrenim gören öğrencilerin kitap okuma alışkanlığına ilişkin tutumları nasıl gelişmiştir?" şeklindedir. Araştırmanın alt problemleri ise; “ Öğrencilere ait bazı demografik bilgilerin okuma alışkanlığ 1 ile anlamlı farklılık göstermekte midir?" şeklinde tanımlanabilir.

\section{Çalışmanın Amacı}

$\mathrm{Bu}$ çalışmada spor bilimleri fakültesi öğrencilerinin kitap okumaya yönelik bakış açıları ve tutumları incelenmek istenmiştir.

\section{YÖNTEM}

Araştırmada tarama modeli kullanılmıştır. Çalışmanın evreni, Marmara Üniversitesi ve İstanbul Üniversitesi Spor Bilimleri fakültesinde eğitim görmekte olan tüm öğrencileri kapsamaktadır. Araştırmanın örneklemini ise, yine bu üniversitelerde eğitim görmekte olan Beden Eğitimi
Öğretmenliği, Spor Yöneticiliği, Antrenörlük Eğitimi ve Ortak bölümlerinden tesadüfî örnekleme yöntemiyle tespit edilen 214 öğrenciden oluşmaktadır. Çalışma grubunun belirlenmesinde kolay ulaşlabilir örnekleme yöntemi kullanılmıştır.

\section{Veri Toplama Araci}

Araştırmada veri toplama aracı olarak "Kitap Okuma Alışkanlığına İlişkin Tutum Ölçeği" kullanılmıştır. 21'i olumlu, 9'u olumsuz 30 tutum maddesinden oluşan ölçek Gömleksiz (2004) tarafından geliştirilmiştir. Araştırmacı tarafından üniversite öğrencileri üzerinde gerçekleştirilen geçerlik ve güvenirlik çalışmasında tüm ölçeğe ilişkin Cronbach Alpha güvenirlik katsayısı 0.88 olarak bulunmuştur. Seçeneklerin; 'Tamamen Kat1liyorum', 'Kat1liyorum', 'Kismen Katıliyorum', 'Katılmıyorum' ve 'Hiç Katılmıyorum' biçiminde sıralandığı ölçeğin faktör yapısını belirlemek amacıyla, faktör analizi yöntemlerinden döndürülmemiş ve asal eksenlere göre döndürülmüş (varimax rotated) temel bileşenler analizinden yararlanılmışır. Analiz sonuçlarına göre ölçekte 6 faktörün yer aldığ belirlenmiş ve bu faktörler; "Sevgi", "Alışkanlık", "Gereklilik", "İstek", "Etki" ve "Yarar" başlıkları altında toplanmıştır. Ölçekte bulunan maddelerin faktör yükleri 0.36 ile 0.63 arasında değişmektedir. Ölçeğin her bir alt boyutuna ilişkin güvenirlik katsayıları 0.70 ile 0.79 arasında değişmektedir.

30 maddeden oluşan ve olumlu tutum maddelerinin "Kesinlikle Katıliyorum" seçeneğinden başlayarak $5,4,3,2,1$, olumsuz tutum maddelerinin ise ters yönde işleyecek şekilde 1, 2, 3, 4, 5 olarak puanlandığı bu tutum ölçeğinden alınabilecek en yüksek puan 150 , en düşük puan ise 30 olmaktadır. Olumsuz tutum ifadelerinde ise bu derecelendirme ters işlemektedir.

\section{Verilerin Analizi}

Araştırmadan elde edilen veriler bilgisayar ortamına aktarılarak ve SPSS paket programı kullanılarak analiz edilmiştir. Elde edilen verileri betimlemek için yüzde (\%) ve frekans (f) teknikleri kullanılmıştır. Verilerin analizine başlamadan önce verilerin normal dağılım gösterip göstermediği çarpıklık 
(skewness) ve basıklık (kurtosis) değerlerine bakılarak hesaplanmıștır. Beş alt boyuttaki verilerin çarpıklık ve basıklık değerlerinin \pm 2 arasında olduğu tespit edilmiştir. Bu değerler verilerin normal dağılım gösterdiği ş̧eklinde yorumlanır (Büyüköztürk, 2013). Yararlılık alt boyutunda parametrik test varsayımlarının gerçekleşmemiştir. Parametrik test varsayımlarının gerçekleştiği beş alt boyutta demografik özelliklere göre anlamlı bir farklılığın olup olmadığını test etmek için bağımsız gruplarda t-testi; parametrik test varsayımlarının gerçekleşmediği "yararlılık" alt boyutunda ise Mann-Whitney $U$ testi kullanılmıştır. İkiden fazla örneklem ortalaması arasındaki farkın anlamlı olup olmadığını test eden ilişkisiz örneklemler için tek faktörlü varyans analizinden yararlanılmıştır; parametrik test varsayımlarının gerçekleşmediği "yararlılık" alt boyutunda ise Kruskal Wallis $\mathrm{H}$ testi kullanılmıştır. Karşılaştırmalardaki farklılığın kaynağını bulmak amacıyla yapılan Levene homojenlik testi sonuçlarında varyansların eşit olduğu durumlarda "Tukey" testi kullanılmıştır.

\section{BULGULAR}

Tablo 1. Kat1lımcıların Özellikleri

\begin{tabular}{lcc}
\hline Özellikler & $\mathrm{f}$ & $\%$ \\
\hline Cinsiyet & & \\
\hline Kadın & 86 & 40.2 \\
Erkek & 128 & 59.8 \\
\hline Sınıf Düzeyi & & \\
\hline Birinci Sınıf & 72 & 33.6 \\
İkinci Sınıf & 43 & 20.1 \\
Üçüncü Sınıf & 59 & 27.6 \\
Dördüncü sınıf & 40 & 18.7 \\
\hline Üniversite & & \\
\hline Marmara & 120 & 56.1 \\
İstanbul & 94 & 43.9 \\
\hline
\end{tabular}

Tablo 2. Öğrencilerin Kitap Okumaya Yönelik Tutumları

\begin{tabular}{llll}
\hline Alt Ölçekler & $\mathrm{N}$ & $\bar{x}$ & ss \\
\hline Sevgi & 214 & 2.47 & .49 \\
Alışkanlık & 214 & 3.11 & .61 \\
Gereklilik & 214 & 2.82 & .53 \\
İstek & 214 & 3.86 & .91 \\
Etki & 214 & 4.15 & .75 \\
Yarar & 214 & 4.40 & .73
\end{tabular}

Öğrencilerin alt ölçeklerinden elde ettikleri puan ortalamaları göz önünde bulundurulduğunda öğrencilerin en fazla "yarar" ve "etki" değerlerine önem verirken, en az "sevgi" ve "gereklilik" değerlerine önem verdikleri görülmektedir.

Tablo 3. Öğrencilerin Cinsiyete Göre Kitap Okuma Alışkanlığı ve Aralarındaki Farklar

\begin{tabular}{|c|c|c|c|c|c|c|c|}
\hline $\begin{array}{l}\text { Alt } \\
\text { ölçek }\end{array}$ & $\mathrm{C}$ & $\mathrm{N}$ & $\bar{x}$ & SS & $\mathrm{t}$ & $\mathrm{sd}$ & $\mathrm{p}$ \\
\hline \multirow[t]{2}{*}{ Sevgi } & $\mathrm{K}$ & 86 & 2.49 & .43 & \multirow[t]{2}{*}{.364} & \multirow{2}{*}{$\begin{array}{c}21 \\
2\end{array}$} & \multirow[t]{2}{*}{.716} \\
\hline & $\mathrm{E}$ & 128 & 2.46 & .53 & & & \\
\hline \multirow{2}{*}{$\begin{array}{l}\text { Alışka } \\
\text { nlık }\end{array}$} & $\mathrm{K}$ & 86 & 2.96 & .63 & \multirow{2}{*}{$\begin{array}{c}- \\
3.17\end{array}$} & \multirow{2}{*}{$\begin{array}{c}21 \\
2\end{array}$} & \multirow{2}{*}{$\begin{array}{c}.002 \\
*\end{array}$} \\
\hline & $\mathrm{E}$ & 128 & 3.22 & .58 & & & \\
\hline \multirow{2}{*}{$\begin{array}{l}\text { Gerekli } \\
\text { lik }\end{array}$} & $\mathrm{K}$ & 86 & 2.80 & .53 & \multirow[t]{2}{*}{.410} & \multirow{2}{*}{$\begin{array}{c}21 \\
2\end{array}$} & \multirow[t]{2}{*}{.682} \\
\hline & $\mathrm{E}$ & 128 & 2.83 & .53 & & & \\
\hline \multirow[t]{2}{*}{ İstek } & $\mathrm{K}$ & 86 & 4.08 & .92 & \multirow[t]{2}{*}{3.00} & \multirow{2}{*}{$\begin{array}{c}21 \\
2\end{array}$} & \multirow{2}{*}{$\begin{array}{c}.003 \\
*\end{array}$} \\
\hline & $\mathrm{E}$ & 128 & 3.71 & .88 & & & \\
\hline \multirow[t]{2}{*}{ Etki } & $\mathrm{K}$ & 86 & 4.31 & .68 & \multirow[t]{2}{*}{2.67} & \multirow{2}{*}{$\begin{array}{c}21 \\
2\end{array}$} & \multirow[t]{2}{*}{.008} \\
\hline & $\mathrm{E}$ & 128 & 4.04 & .77 & & & \\
\hline
\end{tabular}

Tablo 3'e göre kadınların erkek öğrencilere göre istek değerine daha önem verdiği, erkeklerin ise kadın öğrencilere göre alışkanlığa daha çok önem verdiği görüldü. 
Tablo 4. Cinsiyet değiş̧kenine göre MannWhitney U testi sonuçları

\begin{tabular}{lccc}
\hline & N & $\begin{array}{c}\text { Sira } \\
\text { Ort. }\end{array}$ & $\begin{array}{c}\text { Sira } \\
\text { Top. }\end{array}$ \\
\hline Kadın & 86 & 117.59 & 10112.50 \\
\hline Erkek & 128 & 100.72 & 12892.50 \\
\hline Top & 214 & & \\
\hline
\end{tabular}

Tablo 4'e göre, kadın öğrencilerin kitap okumanın erkek öğrencilere göre daha fazla yararlı buldukları şeklinde bir sonuç ortaya çıkmaktadır.

Tablo 5. Kitap okuma alıșkanlığının Bölümlere Göre Karşılaştırılması

\begin{tabular}{|c|c|c|c|c|c|c|}
\hline $\begin{array}{l}\text { Alt } \\
\text { ölçek }\end{array}$ & $\begin{array}{l}\text { Bölü } \\
\text { m }\end{array}$ & $\mathrm{N}$ & $\bar{x}$ & SS & $\mathrm{F}$ & $\mathrm{p}$ \\
\hline \multirow[t]{4}{*}{ Sevgi } & Öğret & 24 & 2.49 & .49 & \multirow[t]{4}{*}{1.47} & \multirow[t]{4}{*}{.224} \\
\hline & Yönet & 53 & 2.52 & .42 & & \\
\hline & Ant. & 95 & 2.51 & .56 & & \\
\hline & Ortak & 42 & 2.33 & .37 & & \\
\hline \multirow{4}{*}{$\begin{array}{l}\text { Alışk } \\
\text { anlık }\end{array}$} & Öğret & 24 & 2.96 & .59 & \multirow[t]{4}{*}{4.77} & \multirow[t]{4}{*}{$.003^{*}$} \\
\hline & Yönet & 53 & 3.14 & .55 & & \\
\hline & Ant. & 95 & 3.25 & .63 & & \\
\hline & Ortak & 42 & 2.86 & .589 & & \\
\hline \multirow{4}{*}{$\begin{array}{l}\text { Gere } \\
\text { klilik }\end{array}$} & Öğret & 24 & 3.08 & .39 & \multirow[t]{4}{*}{3.38} & \multirow[t]{4}{*}{$.019 *$} \\
\hline & Yönet & 53 & 2.88 & .54 & & \\
\hline & Ant. & 95 & 2.78 & .55 & & \\
\hline & Ortak & 42 & 2.69 & .51 & & \\
\hline \multirow[t]{4}{*}{ İstek } & Öğret & 24 & 4.04 & .76 & \multirow[t]{4}{*}{1.53} & \multirow[t]{4}{*}{.206} \\
\hline & Yönet & 53 & 3.82 & .89 & & \\
\hline & Ant. & 95 & 3.74 & .94 & & \\
\hline & Ortak & 42 & 4.06 & .93 & & \\
\hline \multirow[t]{4}{*}{ Etki } & Öğret & 24 & 4.23 & .74 & \multirow[t]{4}{*}{0.93} & \multirow[t]{4}{*}{.427} \\
\hline & Yönet & 53 & 4.07 & .62 & & \\
\hline & Ant. & 95 & 4.11 & .77 & & \\
\hline & Ortak & 42 & 4.29 & .85 & & \\
\hline
\end{tabular}

Tablo 5 incelendiğinde, öğrencilerin kitap okuma alışkanlığına ilişkin tutum ölçeğinin "alışkanlık" ve "gereklilik" alt boyutundan elde ettikleri aritmetik ortalamalar arasinda bölüm değişkenine göre anlamlı farklılıklar olduğu görülmektedir. Ortaya çıkan anlamlı farkın kaynaklandığı bölümleri belirlemek için uygulanan Tukey testi sonra alışkanlık boyutunda Antrenörlük ( $a . o=3.25)$, Ortak program ( a.o $=2.86)$ öğrencileri arasında ortaya çıkan farkın Antrenörlük Bölümü öğrencileri lehine geliștiği bulunmuştur. Ayrıca yine "gereklilik" alt boyutunda Beden Eğitimi Öğretmenliği ( a.o = 3.08) ve ortak Program ( $a .0=2.68)$ Bölümü öğrencileri arasında ortaya çıkan farkın Beden Eğitimi Öğretmenliği Bölümü öğrencileri lehine geliştiği bulunmuştur. Yararlılık boyutunda yapılan Kruskal Wallis $\mathrm{H}$ testinde bölüm bazında anlamlı sonuç elde edilememiştir.

Tablo 6. Sinıf düzeyine göre Kruskal Wallis testi sonuçları

\begin{tabular}{|c|c|c|c|c|}
\hline Bölüm & $\mathrm{N}$ & $\begin{array}{c}\text { Siralar } \\
\text { ortalamas1 }\end{array}$ & $\begin{array}{c}\text { Kruskal } \\
\text { Wallis H }\end{array}$ & $\mathrm{p}$ \\
\hline 1.Sinif & 72 & 113.61 & 5.87 & .071 \\
\hline 2.Sinif & 43 & 97.72 & & \\
\hline 3.Sinif & 50 & 117.47 & & \\
\hline 4.Sinif & 49 & 92.30 & & \\
\hline
\end{tabular}

Kruskal-Wallis testi kitap okuma isteği alt boyutunda her dört sinıf arasinda da anlamlı farklılıkların bulunmadığını göstermişti.

\section{TARTIŞMA VE SONUÇ}

Çalışmada öğrencilerin kitap okuma alışkanlıkları, kitap okumayı gerekli görme, kitap okumayı sevme, kitap okumaya istekli olma, kitap okumanın etkisi ve yararına ilişkin görüşleri alınmış; cinsiyete, sınıf düzeyine ve öğrenim görülen bölüme göre bir farklılığın olup olmadığı belirlenmeye çalışılmıştır.

Elde edilen sonuçlara göre Spor Bilimleri Fakültesi öğrencileri en fazla "kitap okumanın yararı" ve "kitap okumanın etkisi" değerlerine, en az ise "kitap okumayı sevme" ve "kitap okumayı gerekli görme" değerlerine önem vermişlerdir. 
$\mathrm{Bu}$ çalıșmada kadın öğrencilerin erkek öğrencilere oranla daha olumlu tutumlar sergiledikleri görülmüştür. Kadın öğrencilerin erkek öğrencilere göre kitap okuma isteği değerine daha önem verdiği, erkek öğrencilerin ise kadın öğrencilere göre kitap okuma alışkanlığının olduğu yorumu yapılabilmektedir. Özbay ve diğ., 2008; Yalınkılıç, (2007) yapmış oldukları çalışmalarında da kadın öğrencilerin okumaya daha çok değer verdiği ve daha çok okudukları bulunmuştur. Bu durum bizim çalışmamızla paralellik göstermiştir. Buna ek olarak, Yazıcı (2003), erkek öğrencilerin zamanlarının çoğunu spor yaparak, ekonomi ve açı oturum programları izleyerek geçirdiklerini belirtmiştir. $\mathrm{Bu}$ gibi faaliyetlerle ilgilenen erkek öğrencilerin kitap okumaya yeterince zaman ayırmaması okuma alışkanlığ 1 elde etmelerindeki en önemli engel olarak görülebilir. Bu bulgu ise araştırmanın sonucu ile ters düşmektedir. Spor Bilimleri Fakültesi öğrencilerinin cinsiyet fark1 gözetmeden kitap okumayı sevme alt boyutunda aynı düzeyde önem verdikleri görülmüştür. Bozpolat (2010) tarafından öğretmen adaylarına yapılan çalışmada sevgi alt boyutunda kadın öğretmen adayları lehine anlamlı farkl1lı tespit edilmesi, mevcut araştırmanın cinsiyet değişkenini desteklemektedir. $\mathrm{Bu}$ durum araştırmanın sonucu ile yine paralellik göstermemektedir. Kadın öğrenciler erkek öğrencilere göre kitap okumayı daha fazla yararlı bulmuşlardır. Gömleksiz (2004)'in geleceğin öğretmen adaylarına yapmış olduğu çalışmada yarar alt boyutun kadın öğrenciler lehine anlamlı farkl11ıklar bulmuştur. Bu sonuç, araştırmanın cinsiyet değişkeni sonucunu desteklemektedir.

Kitap Okuma Alışkanlığına İlişkin Tutum Ölçeğinde öğrencilerin "alışkanlık" ve "gereklilik" alt boyutundan elde ettikleri aritmetik ortalamalar arasında bölüm değişkenine göre anlamlı farkl1lıklar olduğu belirlenmiştir. "Alışkanlık" boyutunda Antrenörlük bölümü öğrencileri ile Ortak program öğrencileri arasında ortaya çıkan farkın Antrenörlük Bölümü öğrencileri lehine geliştiği bulunmuştur. Buradan, bu bölümdeki öğrencilerin kitap okumayı daha çok alışkanlık edindikleri yorumu çıkarılabilir. Bununla birlikte "gereklilik" alt boyutunda
Beden Eğitimi Öğretmenliği ve Ortak program bölümü öğrencileri arasında ortaya çıkan farkın Beden Eğitimi Öğretmenliği Bölümü öğrencileri lehine olduğu bulunmuştur. Buradan, bu bölümdeki öğrencilerin kitap okumanın kendini geliştirmek için gerekli olduğu düşüncesinde yorumu çıkarılabilir. Göksel ve diğ., (2016) tarafindan Spor Bilimleri ve Teknolojisi Yüksekokulu'nda öğrenim gören öğrencilere yapılan çalışmada bölüm değişkenine göre sadece sevgi alt boyutunda Beden Eğitimi Öğretmenliği bölümü öğrencileri lehine anlamlı farklılık tespit edilmiştir.

$\mathrm{Bu}$ araştırmanın sonuçlarına göre, üniversite öğrencilerine okuma alışkanlığ kazandırabilmek için onları ders dışı süreçlerde yazılı materyallere yönlendirmek gerekmektedir. $\mathrm{Bu}$ amaçla üniversite kütüphaneleri daha çekici hale getirilmelidir. Çeşitli alanlara yönelik kitap sayıs1 artırılmalıdır. Üniversitede yer alacak etkinlikler öğrencileri okumaya ve araştırmaya yöneltecek şekilde düzenlenmelidir. Öğrencilerin ilgi ve ihtiyaçları göz önünde bulundurularak düzenlenecek okuma ortamları, okumayı gereksinim olarak görecekleri bir şekilde onlara sunulmalıdır.

\section{KAYNAKÇA}

Arıca, A.F. (2008). Okumayı niye sevmiyoruz? Üniversite öğrencileri ile mülakatlar. Mustafa Kemal Üniversitesi Sosyal Bilimler Enstitüsü Dergisi, 10.

Arslan, Y., Çelik, Z., Çelik, E. (2009). Üniversite Öğrencilerinin Okuma Alışkanlığına Yönelik Tutumlarının Belirlenmesi. PÜ Eğitim Fakültesi Dergisi, 26, 113-124.

Aytaç, G. (2002). Edebiyat ve Medya Kitaptan Ekrana Edebiyat, T.C. Kültür Bakanlığı Yayınları, Ankara.

Aytaş, G. (2005). Okuma Eğitimi. Türk Eğitim Bilimleri Dergisi, Cilt 3, Sayı 4, 461-470.

Balat, U.G. (2002). Çocuk-Kitap İlişkisi ve Çocukların Düzeylerine Uygun Kitap Seçimi. Yaşadıkça Eğitim. Sayı: 74-75, 4144.

Bayındır N. (2016). Çocuklarda Yaratıcılık ve Geliştirilmesi. Eğiten Kitap Yayınevi.

Bozpolat, E. (2010). Öğretmen Adaylarının Okuma Alışkanlığına İlişkin Tutumlarının Değerlendirilmesi (Cumhuriyet Üniversitesi 
Eğitim Fakültesi Örneği). Journal of World of Turk, 2(1): 411-428.

Büyüköztürk, Ş. (2013). Veri analizi el kitabı. Ankara: PegemA Yayıncılık.

Çoban A., İleri T. Ve Temir M. (2008). Üniversite Öğrencilerinin Kitap Okuma Alışkanlığına Betimsel Bir Bakış: Amasya Üniversitesi Örneği. Sosyal Bilimler Dergisi, Sayı 19, 50-69.

Edizer, Z. Ç. (2015). Türkçe Öğretmen Adaylarının Kitap Okuma Alışkanlı̆̆ına İlişkin Tutumları İle Üst Bilişsel Okuma Stratejilerini Kullanım Düzeyleri Arasındaki İlişki. K. Ü. Kastamonu Eğitim Dergisi, 23 (2), 645-658.

Esgin, A., Karadağ, Ö. (2000). Üniversite Öğrencilerinin Okuma Alışkanlığı. Popüler Bilim. Eylül 2000, 19-23.

Gömleksiz, M. N., Telo, A. (2003). Eğitim Fakültesi Öğrencilerinin Kitap Okuma Alışkanlığı (Fırat Üniversitesi Eğitim Fakültesi Örneği). I. Sosyal Bilimler Eğitimi Kongresi, 15-17 Mayıs 2003. Milli Eğitim Bakanlığı Öğretmen Yetiştirme ve Eğitimi Genel Müdürlüğü. Dokuz Eylül Üniversitesi Buca Eğitim Fakültesi, İzmir.

Gömleksiz, M.N. (2004a). Kitap okuma alışkanlığına iliş kin bir tutum ölçeğinin geçerlik ve güvenirliği. Fırat Üniversitesi Sosyal Bilimler Dergisi, 14 (2), 185-195.

Kurulgan, M. ve Çekerol, S.G. (2008). Öğrencilerin Okuma ve Kütüphane Kullanma Alışkanlıkları Üzerine Bir Araştırma. Anadolu Üniversitesi Sosyal Bilimler Dergisi, 8(2):237-258.

Kuşdemir Y. ve Güneş F. (2014). Doğrudan Öğretim Modelinin Okuduğunu Anlama Becerilerine Etkisi. Mehmet Akif Ersoy Üniversitesi Eğitim Fakültesi Dergisi, Sayı $32,86-113$.

Odabaş, H., Odabaş, Z.Y. ve Polat, C. (2008). Üniversite Öğrencilerinin Okuma Alışkanlığı: Ankara Üniversitesi Örneği. Bilgi Dünyas1, 9(2), 431-465.

Özbay, M., Bağcı, H., ve Uyar, Y., (2008). Türkçe öğretmeni adaylarının okuma alışkanlığına yönelik tutumlarının çeşitli değişkenlere göre değerlendirilmesi. İnönü Üniversitesi Eğitim Fakültesi Dergisi, 9 (15), 119.

Tanju, E. H. (2010). Çocuklarda Kitap Okuma Alışkanlığı'na Genel Bir Bakış, Aile ve Toplum: Eğitim - Kültür ve Araştırma Dergisi, Y11 11, Cilt 6, Sayı 22, 30-39.

Tel, M., Öcalan, M., Ramazanoğlu, F., Demirel, E.T. (2007). Bazı sosyo-ekonomik değişkenlere göre beden eğitimi ve spor bölümü öğrencilerinin okuma alışkanlıkları.
Furat Üniversitesi Sosyal Bilimler Dergisi, 17 (1), 185-199.

Tokar E.K. (2012). Edirne İli Merkez İlçesinde Bulunan İlköğretim 1. Kademe Öğrencilerinin Okuma Alıșkanlıkları Ve Kütüphane Kullanımları. Trakya Üniversitesi Sosyal Bilimler Enstitüsü, İlköğretim Anabilim Dalı Sinıf Öğretmenliği Bilim Dalı, Yüksek Lisans Tezi.

Yalınkılıç, K. (2007). Türkçe Öğretmen Adaylarının Oku maya İlişkin Tutum ve Görüşleri, Uluslararası Sos yal Araştırmalar Dergisi, 1 (1), 225-241

Yavuz, H. (1996). Denemeler, Boyut Yayıncılık, İstanbul.

Yazıcı, E. (2003). Üniversiteli Gençler S.O.S. Veriyor, Anadolu Gençlik Dergisi, s:33, Ankara.

Yılmaz, B. (2004). Öğrencilerin Okuma ve Kütüphane Kullanma Alışkanlıklarında Ebeveynlerin Duyarlılı̆̆ı. Bilgi Dünyası, $5(2), 115$ - 